\title{
EDUCANDO CONTRA LA CORRIENTE
}

Benjamín Rojas Yauri, Lic.

Facultad de Teología U niversidad Peruana U nión benjamin@teologia.edu.pe

\section{Resumen}

Formar el carácter de los hijos es la mayor responsabilidad de todo padre. Por su parte, la sociedad en la que nos desarrollamos intenta ayudar con ese propósito, pero cuando lo hace, se da origen a una lucha entre padres cristianos y sociedad secular. Esta lucha contra la corriente, se da porque existen diferencias significativas entre los conceptos de hijo y carácter, como también, entre la metodología, valores y principios que presenta la Biblia por un lado y la sociedad por el otro, respecto a la formación del carácter. D ebido a ello, esta investigación, basada en un análisis social y bíblico, responde a las siguientes preguntas: ¿quién es un hijo?, ¿cómo se forma un carácter idóneo?, ¿cuál es la función de la sociedad en la formación del carácter?, ¿cómo formar un carácter idóneo en el contexto social actual? Las respuestas a estas preguntas señalan a las grandes diferencias existentes entre la perspectiva social y la bíblica, como también el camino a seguir desde la perspectiva cristiana si se desea formar un carácter idóneo en aquellos que la Biblia llama, herencia de Jehová.

Palabras clave: Educación, hijos, niños, sociedad, padres, carácter, familia. 
Trabajen los padres por los suyos, con amor, fe y oración, hasta que gozosamente puedan presentarse a D ios diciendo: "H e aquí, yo y los hijos que me dio Jehová" 1 .

Elena $\mathrm{G}$. de W hite

\section{Introducción}

"Formar" es una palabra sencilla pero llena de significado, "construir" es un sinónimo de ella, y "deber" es el verbo que le da sentido cuando se habla del carácter de los niños y la responsabilidad que los padres tienen al respecto. El deber de los padres es formar un carácter idóneo en sus hijos, pues de ello depende su felicidad o infelicidad y la prosperidad o la ruina de su descendencia. ${ }^{2}$

1 Elena G. de White, Palabras de vida del gran maestro (Buenos Aires: Casa Editora Sudamericana, 1991), 153, 154.

2 Elena G. de White dice al respecto, "Hay dos maneras de tratar a los hijos, que difieren diametralmente en principio y en resultados. La fidelidad y el amor, unidos a la sabiduría y la firme$\mathrm{za}$, de acuerdo con las enseñanzas de la Palabra de Dios, darán como resultado felicidad en esta vida y en la venidera. El descuido del deber, la complacencia imprudente, el dejar de restringir o corregir los desatinos de la juventud, darán como resultado la infelicidad y la ruina final de los hijos, y el chasco y la angustia de los padres". Elena G. de White, Hijos e hijas de Dios (Buenos Aires: Casa Editora Sudamericana, 1978), 259.
Sin embargo, aunque parezca contradictorio, al canzar este objetivo es casi imposible en una sociedad que se ha propuesto ayudar a los padresa cumplir este propósito. La sociedad, perturba más y ayuda menos en la formación del carácter de aquellos que más aman los padres, y un ejemplo de ello son las propagandas emitidas en diversos medios de comunicación, por instituciones que dicen tener interés por los niños de nuestra sociedad. Por ejemplo, en una radio local, se escucha lo siguiente:

El sonido de una puerta abriéndose y una voz adolescente que dice: H ola ma, luego una voz fuerte diciendo: ¡0 tra vez con ese cabello, cuántas veces te he dicho que no quiero verte así! Finalmente la voz del locutor dice: ite sientes incomprendido? llama a la defensoría del menor y del adolescente, nosotros deseamos ayudarte. $^{3}$

Este es sólo un ejemplo de las muchas propagandas, legales e ilegales, patrocinadas por entidades formales o informales,

$3 \mathrm{La}$ propaganda mencionada es emitida por diversas radios FM en la ciudad de Lima, fue escuchada en Radio Latina a las 11:00 am. el día 9 de mayo del 2012. 
que desde su particular perspectiva ayudan a formar un carácter armonioso, estable e idóneo en los niños y adolescentes de nuestra sociedad. D ebido a ello, se puede afirmar que, formar el carácter de los hijos de acuerdo a la voluntad de Dios, es una lucha contra la corriente. En este contexto, el presente artículo pretende responder cuatro preguntas: 1) ¿quién es un hijo?; 2) ¿cómo se forma un carácter idóneo?; 3) ¿cuál es la función de la sociedad en la formación del carácter?; y 4) ¿cómo formar un carácter idóneo en el contexto social actual?

\section{¿Q uién es un hijo?}

El Diccionario de la Real Academia Española, define la palabra "hijo" como: "Persona o animal respecto de su padre o de su madre", ${ }^{4}$ sin embargo, definir al ser humano nombrado como hijo no es tan simple como lo presenta el diccionario. ¿Q uién es un hijo?, es una pregunta que requiere un sinnúmero de respuestas, que en realidad, no terminarían por definir su significado.

4 Diccionario de la lengua española: Real Academia Española, 22va ed. s.v. "hijo".
Debido a ello, precisar el significado de lo que es un hijo y cómo se forma un carácter idóneo, son asuntos que están estrechamente relacionados y no pueden ser dejados a merced de una conversación social, esto requiere un "así dice el Señor", y sólo la Sagrada Escritura (SE) puede ayudar a este objetivo. En las páginas de la SE, se lee lo siguiente:

H eaquí, herencia de YH VH son los hijos, Y una recompensa el fruto del vientre. C omo saetas en manos del valiente, $A$ sí son los hijos habidos en la juventud. ¡C uán bienaventurado es el varón que llena su aljaba de ellos! N o será avergonzado cuando hable con sus enemigos en la puerta. ${ }^{5}$

Este concepto es mayor del que se puede comprender, una serie de palabras son aludidas, entre ellos verbos, sustantivos y pronombres como: herencia, recompensa, saetas, bienaventuranza, jactancia, entre otras. Sin embargo, la SE presenta la identidad de un hijo más am-

5 Sociedad Bíblica Iberoamericana, Santa Biblia: La Biblia Textual, 2a. ed. (Venezuela: Sociedad Bíblica Iberoamericana, Inc., 2008), Sal 127:3-5. En adelante BTX. 
pliamente. ${ }^{6}$ Sistematizar y completar todo ese contenido sería un desafío titánico, por lo tanto, en este estudio sólo se tratarán algunos aspectos pertinentes a esta investigación y surgidos del texto mencionado.

Si el hijo es herencia, entonces es más que un regalo, es un regalo con responsabilidad, es un regalo por el cual uno puede ser juzgado. Esta es una realidad social, pues, aunque se intente librar de su responsabilidad al padre de un hijo indeseable, la realidad es que ello es imposible. El hijo es una herencia que requiere ser desarrollada, es se116 mejante a una planta, que si es adecuadamente cuidada, da fruto y gratificación, de lo contrario sólo sirve para ser quemada.?

6 Algunos textos bíblicos que hagan referencia al tema son: Gn 1:28; 50:23; $15: 4,5 ; \quad 24: 60 ; \quad 30: 1,2 ; \quad 33: 5 ; \quad 41: 51,52$; 48:4; Dt 28:4; Jos 24:3,4; 1 Sa 1:19,20,27; 2:20,21; 1 Cr 28:5; Job 1:2; 5:4; 42:12-16; Sal 128:3,4; Pr 17:6; 27:11; 31:28; Is 8:18; Jer 50:9. Véase, Guillermo D. Powell, ed. El tesoro del conocimiento bíblico: Referencias bíblicas y pasajes paralelos (Bellingham, WA: Logos Research Systems, 2011), Sal 127:3-5.

$7 \mathrm{Al}$ comentar 1 Co 3:13 "la obra de cada uno se hará manifiesta, porque el día la mostrará, pues por el fuego será revelada, y el fuego probará la clase de obra de cada uno", el Comentario Bíblico
Si el hijo es una recompensa, es un ente que trae gratificación, pero una gratificación basada en el esfuerzo y no en el azar. Por lo tanto, aunque el hijo pertenece a su padre desde el día que nace, también llega a ser hijo por el esfuerzo y la dedicación que éste ponga en él, es decir, el hijo es al go que se gana y no sólo se posee. Además, si el hijo es como una saeta - flecha - en manos del valiente, se debe a que es un instrumento valioso en las manos adecuadas, una saeta siempre es una saeta, pero su efectividad depende de aquel que

Adventista dice: "La verdadera naturaleza de la fe de los que se llaman hijos de Dios se manifiesta en tiempos difíciles. Si están verdaderamente convertidos y han sido debidamente adoctrinados con el puro Evangelio de Jesucristo, los fuegos de la persecución y de la prueba sólo harán que se fortalezca su fe y que su amor por el Señor brille aún más. Por otro lado, si han recibido una instrucción defectuosa, compuesta de una mezcla de filosofía humana y componendas con el mundo, su fe no resistirá la prueba de las dificultades y se apartarán de Cristo y de su iglesia. Sólo los que hayan edificado fielmente sobre el verdadero fundamento, Jesucristo, y hayan usado materiales resistentes, verán que su obra perdura hasta el fin". "Por el fuego será revelada" [1Co 3:13], Francis D. Nichol, ed. Comentario Bíblico Adventista del Séptimo Día, 9 vols. (Buenos Aires: Asociación Casa Editora Sudamericana, 1992), 6:673. 
lo empuña, por lo tanto, todo hijo es un instrumento perfecto, pero el que llegue a ser eficaz depende de quien lo posee.

También esimportantenotar, que el texto - aunque habla de la familia en su totalidad - coloca a la familia en un contexto de guerra. ${ }^{8}$ Por lo tanto, los hijos, como parte de ella, están bajo ataque. Sin embargo, en esta guerra, los hijos cumplen un rol indispensable para la victoria 0 la derrota, no sólo de ellos, sino de toda la familia, es decir, los hijos dan victoria o derrota a la familia, la coronan o la sepultan, son los hijos los que determinan el futuro de la familia a pesar de que el futuro de ellos es determinado por los padres de esa familia.

8 Mervin Breneman al comentar Salmos 127 dice: "La última frase muestra que este cuadro de bendición no excluye problemas ni ataques del enemigo. Aun en este contexto de una sociedad donde hay luchas, la enseñanza del Salmo sigue en pie; sin la dirección y la bendición de Dios todo el esfuerzo y todos los cuidados humanos son vacíos, son en vano". Véase, Dionisio Ortiz, ed. Salmos, ed. Daniel Carro, José Tomás Poe, y Rubén O. Zorzoli, 24 vols., Comentario Bíblico Mundo Hispano, vol. 8 (El Paso, TX: Editorial Mundo Hispano, 1993), 401.
¿Quién es un hijo?, fue la pregunta que abrió este diálogo, y aunque se intentó responder a esta pregunta, se debe reconocer que si se ha conseguido algo, esto es parcial y no completo, porque un hijo es todo lo mencionado y mucho más.

\section{¿Cómo se forma un carác- ter idóneo?}

Responder esta pregunta podría ocupar una gran cantidad de volúmenes, y para hacerlo primero se debe definir carácter y luego ver aquello que lo hace idóneo. En 1895 Smiles decía, "El carácter es una de las mayores fuerzas motrices que existen

en el mundo". ${ }^{9}$ Hoy se puede leer en el diccionario que carácter es la "Personalidad, idiosincrasia, modo de ser de las personas... Característica o particularidad que distingue a unas personas o cosas de otras". ${ }^{10}$ Sin embargo, cabe preguntarse aquí ¿Q ué es el carácter para Dios? Y ¿cuál es el carácter idóneo para El?, aunque este sucinto documento no pretende responder de forma completa estas comple-

9 Samuel Smiles, Character (Teddington, Inglaterra: Echo Library, 2006), 1.

10 Gran diccionario de la lengua española Larousse, s.v. "carácter". 
jas preguntas, se presentan algunas citas que se espera ayuden a este propósito,

Vosotros pues sed perfectos, como vuestro Padre celestial es perfecto. ${ }^{11}$

$V$ iene el príncipe de este mundo -dice Jesús mas no tiene nada en mí. No había en él nada que respondiera a los sofismas de Satanás. El no consintió en pecar. $\mathrm{Ni}$ siquiera por un pensamiento cedió a la tentación. A sí también podemos hacer nosotros. La humanidad de C risto estaba unida con la divinidad. Fue hecho idóneo para el conflicto mediante la permanencia del Esórítu Santo en él. Y él vino para hacernos participantes de la naturaleza divina. M ientras estemos unidos con él por la fe, el pecado no tendrá dominio sobre nosotros. Dios extiende su mano para alcanzar la mano de nuestra fe y dirigirla a asirse de la divinidad de C risto, a fin de que nuestro carácter pueda alcanzar la perfección. ${ }^{12}$

\section{Aunque, las citas no definen}

\section{BTX, Mt 5:48.}

12 Elena G. de White, El deseado de todas las gentes (Buenos Aires: Casa Editora Sudamericana, 1991), 98, 99. el carácter, señalan sus características: santo, perfecto, partícipe de la natural eza divina. Es decir, el carácter del hombre debe ser el carácter de Dios, aunque ello no signifique que la esencia y el ser de Dios deben llegar a ser la esencia y el ser del hombre, para decir que un ser humano tiene carácter. Así, lo primero que se puede decir, es que el carácter es una característica divina que el ser humano comparte y su idoneidad, depende de cuán bien refleje la característica divina.

Es decir, un carácter idóneo es aquel que manifiesta mejor el carácter del Señor Jesús, modelo terrestre de la perfección celestial. Por lo tanto, un carácter idóneo desde el punto de vista bíblico, es el resultado del some timiento y obediencia a las enseñanzas, principios, leyes, normas y filosofía de vida presente en la Biblia. Consecuentemente se puede afirmar, que ciertamente el carácter es aquello que identifica al ser humano con la divinidad, o sea, el carácter es una característica humana común y no particular, identifica no en el sentido excluyente sino en un sentido incluyente, une y no separa, permite que el ser humano haga parte del gran grupo de 
hijos de Dios, cuyo carácter es uno y no uno diferente del otro. Por lo tanto, el carácter desde el punto de vista bíblico, es una característica común y similar en todos aquellos que reflejan el carácter de Dios, consiguientemente, se puede afirmar de toda característica humana no amoldada a este patrón, es una deformación del carácter.13

\section{¿Cómo se forma el carácter?}

Luego de este corto intento por definir carácter, se debe tratar de responder la pregunta ¿Cómo se forma el carácter? y en este sentido la responsabilidad que cada padre tiene respecto a su prole es grande, pues desde una perspectiva bíblica, el carácter divino se desarrolla por

13 "Es la voluntad de Dios que el hombre refleje el carácter divino, y ese carácter puede resumirse en la palabra 'amor", "Los mandamientos" [Mt 19:17], Nichol, ed., 5:446. Para ver algunas citas que ayudan a entender este concepto en Elena G. de White, véase, Elena G. de White, En los lugares celestiales (Buenos Aires: Asociación Casa Editora Sudamericana, 1968), 281; Elena G. de White, Reflejemos a Jesús (Buenos Aires: Asociación Casa Editora Sudamericana, 1985), 243; Elena G. de White, Alza tus ojos (Buenos Aires: Casa Editora Sudamericana, 1991), 26. contemplación, ${ }_{14}^{14}$ sin embargo, el hijo en sus tiernos años sólo puede ver a Dios a través de sus padres. Debido a ello, el padre sólo podrá formar un carácter idóneo en sus hijos, luego de haber formado un carácter idóneo en él. Esto se manifestará en cada detalle de su vida, como la limpieza del hogar, ${ }^{15}$ la salud, ${ }_{16}^{16}$ la música, entre tantas otras cosas que forman o deforman el carácter de los niños. También, se debe recordar, que el ser humano puede desarrollar 0 degradar su carácter, pues como lo señala I báñez,

...las bestias aún actuando como bestias no se degeneran, pues no 119 se puede decir del León que mata a un pobre cervatillo que es un

14 "Por tanto, nosotros todos, mirando a cara descubierta como en un espejo la gloria del Señor, somos transformados de gloria en gloria en la misma imagen, como por el Espíritu del Señor”. 2 Corintios 3:18

15 Elena G. de White, Joyas de los testimonios (Buenos Aires: Asociación Casa Editora Sudamericana, 1979), 2: 437-38.

16 Elena G. de White dice que, "Toda influencia que afecte a la salud del cuerpo repercute en el espíritu y en el carácter". Elena G. de White, Ministerio de curación (Buenos Aires: Casa Editora Sudamericana, 1991), 293. 
degenerado, pues sólo cumple con la ley natural que el pecado ha impuesto en él, sin embargo el pecado no lo degenera. El hombre en cambio inicia con un pequeño problema "estropeándose ligeramente; luego, el mal hábito o vicio arraigado, lo lleva por caminos de miseria, hiriéndose a sí mismo, y dejando heridos a los que tiene alrededor. D e aquí la importancia de la educación".17

Debido a ello, cada hábito, cada palabra, cada acción y comportamiento del niño, debe ser estrictamente vigilado y moldeado de acuerdo a la voluntad de Dios expuesta en la Sagrada Es120 critura, pues sólo ello garantiza la formación de un carácter idóneo en el ser humano. Finalmente se debe señalar, que aunque el ser humano a consecuencia del pecado, vive la experiencia de la degradación, ello no determina su futuro, pues existe esperanza para aquellos que tienen padres dispuestos a asumir su responsabilidad, aunque al hacerlo tengan que luchar contra la corriente.

17 Diego Ibáñez Langlois, Educar contracorriente (Madrid: Ediciones Internacionales Universitarias S.A., 2009), 17.

\section{¿Cuál es la función de la sociedad en la formación del carácter?}

El día que un hijo llega al seno materno también llega al seno de la sociedad, y aunque su influencia es casi imperceptible en los primeros meses y años, esta es en mayor grado negativa que positiva desde una perspectiva cristiana. Algunos ejemplos de esto se pueden ver en los diversos mensajes que se han preparado para ellos y que se exponen a través de los medios de comunicación, que influyen aun en el gusto quelos niños tienen por ciertas comidas o bebidas. $^{18}$

Un análisis simple de los mensajes visibles a los que se expone a los menores a través de las caden as televisivas que dicen estar diseñadas para niños y adolescentes, muestra esta realidad. Los programas en estos canales, supuestamente culturales y edu-

18 "Los medios de comunicación, las películas y hasta los comerciales contribuyen en gran cantidad a las actitudes de los niños con respecto a las comidas que les gustan". Scott Turansky y Joanne Miller, ¿Enojados?: Cómo cambiar en su familia la frustración por formación del carácter (Grand Rapids, MI: Editorial Portavoz, 2007), 129. 
cativos, están llenos de mensajes antibíblicos; la ostentación, el despilfarro, la desconsideración, el evolucionismo, el espiritismo, el humanismo y tantos otros mensajes antibíblicos son pregonados y transmitidos a los niños como si se tratarán de ideas y cualidades nobles y deseables.

0 tra gran cantidad de mensajes llegan a la mente de los menores, mediante los audios. H oy nuestra sociedad no es silente. Para los niños del mundo posmoderno los sonidos son parte de su vida, el silencio significa muerte y desesperación; debido a ello se los ve con aparatos que les permiten estar en contacto con el sonido en todo lugar y a toda hora. Los M p3 y losiPhone han invadido la sociedad y son el medio por el cual los mensajes preparados para ellos llegan a sus mentes. Pero iqué transmiten?, cantantes famosos, ídolos de los pequeños, quien es cantan melodías cuyas letras y sonidos conducen a los niños y adolescentes por caminos de promiscuidad, odio, violencia, depresión, rebeldía, muerte, drogas y degradación permanente.

Por otro lado, la lectura, reconocida como el mejor sistema para educar al hombre, hoy ya no es confiable, los mensajes escritos que están a disposición de los hijos de esta sociedad, no siempre educan. La buena lectura ha ido disminuyendo con el tiempo, hoy abundan libros grandes y pequeños que elaborados para las mentes más jóvenes, dicen promover la lectura a costa de transmitir mensajes antibíblicos. La sociedad general, sin embargo, no ve peligro en los mensajes que estos materiales transmiten, pues formar el carácter, para ellos no tiene que ver con desarrollar una característica divina en el ser humano, sino algunas de las características sociales y culturales, regularmente aceptadas.

Debido a lo mencionado, se puede asegurar que la sociedad tiene contacto directo con los niños y que este contacto es intencional, puesla sociedad desea formar en ellos un carácter que los identifique con el mundo que les tocó vivir. En este punto cabe preguntarse, ¿C uánta posibilidad existe de que la sociedad forme un carácter idóneo en los niños y adolescentes? No se puede olvidar, que el carácter idóneo para el verdadero cristiano es uno y para la sociedad general es otro. D ebido a ello, la formación del carácter de los hijos que 
el Señor ha entregado a cada padre como parte de su herencia, es una lucha contra la corriente, pero es una lucha en la que existe posibilidad de victoria.

Además de lo señalado, no se puede desconocer la realidad social que le toca vivir al niño en la actualidad; ya Medina Leal, desarrollaba una serie de tópicos que mostraban la realidad social que enfrentaba el niño de hace tres décadas, 19 hoy todas ellas se han multiplicado y son más desfavorables para la formación de un carácter idóneo desde la óptica de Dios. Por eso, responder a la pregunta propuesta - ¿C uál es la función de la sociedad en

122 la formación del carácter? No es alentadora, pues aunque su función desde una perspectiva bíblica debería ser positiva, la realidad dice, que su función actual es negativa. Sin embargo, esto no quiere decir que se deba aislar a los niños de la sociedad, pues ello podría ser aún más perjudicial, pero si quiere decir, que todo padre debe estar alerta y en permanente actitud defensiva respecto al quehacer educativo de la sociedad sobre los niños.

19 Carlos Medina Leal, ¿Qué sucede con nuestros hijos?: la explicación breve y sencilla de los problemas emocionales más comunes en la infancia y adolescencia (Guadalajara: Editorial Conexión Gráfica, 1989).

\section{¿Cómo formar un carác- ter idóneo en el contexto social actual?}

Se ha dicho, que el más valioso legado que el padre puede de jar al hijo es un carácter noble e idóneo, ${ }^{20}$ sin embargo, como ya se dijo, este más que un legado es un deber que el padre tiene frente a la sociedad y su familia. ${ }^{21}$ Pues al cumplir esta tarea, provee a sus hijos de un carácter que lo habilita para alcanzar la salvación, y ciertas habilidades que lo ayudarán a superar los problemas que enfrentará en el transcurso de su vida.

20 Elena G. de White dice al respecto, "Mejor que cualquier herencia de riquezas que podáis dejar a vuestros hijos será la dádiva de un cuerpo vigoroso, una mente sana y un carácter noble". White, Ministerio de curación, 284.

21 White dice al respecto, "Los padres deben ser impresionados con su obligación de dar al mundo hijos que tengan caracteres bien desarrollados; hijos que tengan poder moral para resistir a la tentación y cuya vida sea un honor para Dios y una bendición para sus prójimos. Los que entren en la vida activa con principios firmes, estarán preparados para mantenerse límpidos en medio de la corrupción moral de este siglo corrupto". Elena G. de White, Conducción del niño (Buenos Aires: Casa Editora Sudamericana, 1991), 176. 
Existe en la actualidad gran cantidad de material escrito al respecto, por ejemplo, I báñez Langlois aborda diez características que son necesarias desarrollar en el niño y el adolescente y cómo hacerlo. ${ }^{22}$ Sin embargo, frente a esta realidad, cabe preguntarse si sólo leyendo todo lo escrito, el padre se habilita para formar el carácter que tanto anhela desarrollar en sus hijos. No está mal leer, sin embargo ello es insuficiente. Elena de W hite al compartir su experiencia como educadora de hijos, dice cosas que podrían ayudarnos a comprender el cómo se consigue desarrollar en el hijo el carácter idóneo del que se está hablando, ella dice,

Cuando me sentía irritada y tentada a decir palabras que me avergonzarían, me callaba, salía de la habitación y pedía a Dios que me diera paciencia para enseñar a esos niños... D ebiéramos hablar bondadosa y pacientemente, recordando siempre cuán extraviados somos y cómo queremos ser

22 Ibáñez desarrolla en su libro, tópicos como: la obediencia, la sinceridad, el orden, la responsabilidad, la constancia, la fortaleza, el respeto, la sobriedad, el ejemplo, el pudor. Véase, Ibáñez Langlois, 1-128. tratados por nuestro Padre celestial. Estas son las lecciones que deben aprender los padres, y cuando las hayáis aprendido, seréis los mejores alumnos de la escuela de C risto y vuestros hijos serán los mejores hijos. En esta forma podéis enseñarles el respeto de D ios y la observancia de su ley, porque tendréis un excelente dominio sobre ellos y al hacer esto los estáis educando para que en la sociedad sean niños que serán una bendición para los que los rodean. L os estáis preparando para ser colaboradores con D ios. ${ }^{23}$

Algunos verbos y frases verbales destacados en esta cita son conocidos como palabras de acción. Es decir, los padres que desean cumplir la gran tarea de su vida - formar caracteres idóneos en sus hijos-, deben hacer cosas de forma deliberada y consciente, cosas que estén cimentadas en la SE, leer es una de ellas, pero actuar con firmeza y decisión en el momento oportuno es más importantequela teoría del actuar.

En este sentido, es necesario señalar, que aunque el carácter pertenece a los niños, los responsables de forjarlo son los

23 White, Conducción del niño, 238-239. El énfasis es nuestro. 
padres y si vemos en ellos defectos inaceptables valdría la pena reflexionar en la siguiente declaración, que recuerđa algo mencionado anteriormente,

$M$ anifestad la mansedumbre y amabilidad de Cristo al tratar con los pequeñuelos rebeldes. Te ned siempre presente que recibie ron su perversidad como herencia desu padre o desu madre. Tened por tanto paciencia con los niños que heredaron vuestros propios rasgos de carácter. ${ }^{24}$

Sin embargo, Elena $G$. de W hite, no piensa que este problema sea algo irremediable e imposible, pues ella continúa 124 diciendo lo siguiente,

Los padres deben confiar implícitamente en el poder de Cristo para transformar las tendencias al mal que fueron transmitidas a sus hijos. Tened paciencia, padres y madres. Con frecuencia, vuestra negligencia pasada dificultará vuestra obra; pero Dios os dará fuerza si queréis confiar en él. 0 brad sabia y tiernamente con vuestros hijos. ${ }^{25}$

24 Elena G. de White, El hogar cristiano (Buenos Aires: Asociación Casa Editora Sudamericana, 1995), 155. El énfasis es nuestro.

25 Ibíd.
Sin embargo, como se sostie ne en este artículo, formar un carácter idóneo en el contexto social actual, es una lucha contra la corriente. Esto se debe a que la sociedad no comparte los valores y principios bíblicos. Por ejemplo, mientras que la socie dad pregona el respeto por los deseos y gustos de los niños, el verdadero cristiano entiende que muchas veces deberá imponer la voluntad de Dios sobre las inclinaciones y gustos de sus hijos. ${ }^{26} 0$ tro aspecto, está relacionado con el poder de decisión que los niños deben tener. Mientras que la sociedad pide que los niños tomen sus propias decisiones, el padre cristiano sabe que el poder de decisión le pertenece, ${ }^{27}$ aunque ello no

26 "Padres si queréis la bendición de Dios, proceded como procedió Abraham. Reprimid el mal y fomentad el bien. Será necesario dar algunas órdenes en lugar de consultar las inclinaciones y gustos de los hijos". White, Conducción del niño, 218.

27 "El verdadero problema es: ¿Quién decide? A menudo, es el niño quien decide sobre su propia necesidad. Y aquí está el drama de los que somos padres: ¿Cómo podemos pensar en dejar al niño poder de decisión? El poder de decisión es nuestro. El niño pide y es justo que pida... Nosotros debemos preguntarnos si es justo decirles siempre que sí o que no... Pero hay algo que es 
signifique que deba ser un autoritario irracional. También, la sociedad dice que es necesario que los padres pasen tiempo con sus hijos,28 mientras que el verdadero cristiano sabe que la madre cumple un rol insustituible, y que el tiempo que ella pase con sus hijos no debe ser interrumpido por ninguna otra labor, por lo menos durante los primeros ocho años.

\section{Debido a ello se afirma que el deber de los padres cristianos}

justo siempre: el poder de decisión deben tenerlo siempre los padres". Victoria Maioli Sanese, Padres e hijos: La relación que nos constituye, trad., Marta Graupera (Madrid: Ediciones Encuentro S.A., 2006), 104-105.

28 "Muchos padres creen que no tiene importancia separarse de un niño pequeño (nos referimos con esto a niños desde pocas semanas hasta 4 años de edad) y fácilmente los confía, por períodos más o menos largos, a parientes o amigos, o incluso a alguna institución $\mathrm{u}$ hogar infantil... Ciertamente, los cuidados maternos que proporcionan al niño íntimo y cálido intercambio de afecto, de ternura, son tan indispensables para su desarrollo armonioso como el alimento y las vitaminas". Andre Berge, Las Dificultades de Vuestro Hijo (Madrid: Ediciones Morata S.A., 1987), 23. Se debe aclarar que Berge, sostiene la idea de que lo importante no es la presencia del padre, sino la presencia de alguien con quien el niño desarrolle un vínculo de intimidad. para con sus hijos, es sólo el deber de ellos y la misión de éstos debe ser considerada, una misión personal y no social, pues parafraseando una oración por la familia se podría decir, que los padres cristianos al orar dicen,

En ningún instante permitas que olvidemos que la felicidad y la estabilidad de esta familia dependen de qué tan cerca vivamos de tu amor y de tus leyes ${ }^{29}$ y no de las leyes y el amor que la sociedad dice tener por nuestros hijos.

O tras cosas puntuales que, los padres deben hacer para formar un carácter idóneo en sus hijos es: cuidar de sus decisiones durante el embarazo, ${ }^{30}$ enseñarles los mandamientos de

29 Héctor Francisco Afanador Cabrera, Hijos felices y equilibrados: bases para formar un hogar estable y amoroso (Colombia: Ecoe Ediciones, 2005), 200.

30 "Si antes del nacimiento de éste, la madre procura complacerse a sí misma, si es egoísta, impaciente e imperiosa, estos rasgos de carácter se reflejarán en el temperamento del niño. Así se explica que muchos hijos hayan recibido por herencia tendencias al mal que son casi irresistibles". Elena G. de White, Consejos sobre el régimen alimenticio (Buenos Aires: Casa Editora Sudamericana, 1991), 255. 
Dios, 31 "hablarles con bondad, ser pacientes con ellos, velar en oración suplicándole al Señor que modele y conforme los corazones de sus hijos... presentar a sus retoños un vívido ejemplo del modelo divino" ${ }^{32}$

\section{Existen cuatro aspectos que} se deben enfatizar al formar el carácter de los hijos: el respeto, la obediencia, la reverencia y el dominio propio. ${ }^{33}$ Sobre el respeto, Noro dice: si el niño, "muestra una actitud de respeto significa que exhibe una conducta habitual de consideración y no de avasallamiento frente a los otros". ${ }^{34}$ Pero el respeto más

31 "Enseñad a vuestros hijos que los mandamientos de Dios deben constituir la regla de su vida. Puede ser que las circunstancias los alejen de sus padres y sus hogares, pero las lecciones de instrucción dadas en la niñez y la juventud les serán una bendición durante toda su vida". White, Conducción del niño, 42.

32 Elena G. de White, Cada día con Dios (Buenos Aires: Asociación Casa Editora Sudamericana, 1992), 219.

33 Elena G. de White, Consejos para los maestros, padres y alumnos acerca de la educación cristiana (Buenos Aires: Asociación Casa Editora Sudamericana, 1991), 83.

34 Jorge Eduardo Noro, Educar juntos: escuela y familia (Buenos Aires: MV Ediciones S.R.L., 2010), 72. importante que se debe enseñar a los niños, es el respeto por Dios y su palabra.

La obediencia, es otra de las lecciones valiosas que el niño debe aprender, ${ }^{35}$ pues la desobediencia es un problema muy antiguo. Ya "en una inscripción asiria del año 2000 a.C. se lee: Quétiempos son éstos; los hijos ya no obedecen a sus padres". 36 La obediencia es necesaria, pues la desobediencia a los padres dará como resultado desobediencia a las leyes civiles y principalmente a las leyes divinas. La idea de enseñar obediencia no es formar un niño soldado, ${ }^{37}$ sin embargo, la obediencia unida al respeto sientan las bases para el desarrollo de un carácter que refleje el carácter divino.

35 Elena G. de White dice, "una de las primeras lecciones que necesita aprender el niño es la obediencia. Se le debe enseñar a obedecer antes que tenga edad suficiente para razonar". Elena G. de White, La educación (Buenos Aires: Asociación Casa Editora Sudamericana, 1991), 279.

36 Ibáñez Langlois, 21.

37 Para la problemática del niño soldado, véase, Marcela Arellano Velasco, "Los niños soldados, reto de un nuevo modelo de seguridad," Convergencia 11, No. 34 (2004): 113-37. 
La reverencia, es otra de las lecciones importantes que se debe enseñar a los niños, fue una característica de hombres como Daniel, ${ }^{38}$ y es la característica de todo verdadero adorador.

Sobre el dominio propio, García dice que se trata de la "capacidad de un sujeto para comportarse de forma coherente con las convicciones y propósitos el egidos por uno mismo". 39 Sin embargo, desde el punto de vista bíblico, el dominio propio consiste en comportarse de forma coherente con la voluntad y propósito divino, que muchas veces es contraria a la convicción y propósito humano.

Desarrollar el carácter divino en los hijos, es el gran desafío que enfrenta todo padre y aunque esto pueda parecer un blanco inalcanzable, no se puede negar que la perfección y no menos, es el deseo de Dios para el carácter de sus hijos, porque

38 Elena G. de White, Mensajes para los jóvenes (Buenos Aires: Asociación Casa Editora Sudamericana, 1991), 30.

39 Rafaela García, Cruz Pérez, y Juan Escámez, La educación ética en la familia (Bilbao: Editorial Desclée de Brouwer, 2009), 98. como dice Elena G . de W hite,

... en la ley de Dios no hay misterios. El intelecto más débil puede captar esos principios para regular su vida y formar su carácter de acuerdo con el modelo divino. Si los hijos de los hombres obedecen esta ley lo mejor que pueden, obtendrán poder intelectual y capacidad de discernimiento para comprender aún más los propósitos y los planes de D ios...". 40

\section{A plicación práctica}

Todo padre puede crear algún método para evaluar la influencia que la sociedad tiene en los conocimientos, valores, principios y conductas de sus hijos. En este caso, se presenta una técnica puesta en práctica por el autor del artículo, que podría servir de idea o modelo para situaciones similares.

Este cuestionario debe ser evaluado, y para ello se debe tomar en cuenta los cambios que sufren las ideas en base a las edades y los círculos sociales con los que se relacionan los niños, esto es fundamental para determinar

40 Elena $\mathrm{G}$. de White, $A$ fin de conocerle (Buenos Aires: Casa Editora Sudamericana, 1991), 296. 


\section{Técnica: Cuestionario sobre conocimientos, valores, prin- cipios y conductas}

\begin{tabular}{|c|c|c|c|}
\hline PREGUNTA & $\begin{array}{l}\text { NINONO } 01 \\
\text { (5 años) }\end{array}$ & $\begin{array}{l}\text { NINOO O2 } \\
\text { (7 años) }\end{array}$ & $\begin{array}{l}\text { NINO } 03 \\
\text { (9 años) }\end{array}$ \\
\hline $\begin{array}{l}\text { ¿H ace cuántos años } \\
\text { vivió el dinosaurio } \\
\text { más antiguo? }\end{array}$ & Catorce mil años & 120 años & Miles de años \\
\hline $\begin{array}{c}\text { ¿Cuáles son los } \\
\text { derechos de los niños? }\end{array}$ & Ser amado y comer & $\begin{array}{l}\text { Comer, jugar y } \\
\text { pasear }\end{array}$ & $\begin{array}{l}\text { Tener un nombre, tener una } \\
\text { familia, ser alimentado y en } \\
\text { caso de emergencia el niño } \\
\text { debe ser rescatado primero }\end{array}$ \\
\hline $\begin{array}{c}\text { ¿Cuáles son los } \\
\text { deberes de los niños? }\end{array}$ & $\begin{array}{l}\text { Portarse bien, ser } \\
\text { responsable, } \\
\text { obediente y } \\
\text { ayudador }\end{array}$ & $\begin{array}{c}\text { Ser respetuoso y } \\
\text { tender su cama }\end{array}$ & $\begin{array}{c}\text { Ordenar, limpiar, barrer, hacer } \\
\text { su tarea y cuidar a sus } \\
\text { hermanos si es el o la mayor }\end{array}$ \\
\hline $\begin{array}{c}\text { ¿Cuándo esta } \\
\text { permitido mentir? }\end{array}$ & $\begin{array}{c}\text { Cuando está la } \\
\text { mamá }\end{array}$ & En ningún momento & En caso de emergencia \\
\hline $\begin{array}{c}\text { ¿Es necesario } \\
\text { conseguir más dinero? } \\
\text { ¿Por qué? }\end{array}$ & $\begin{array}{l}\text { No, porque eso no } \\
\text { vale nada }\end{array}$ & $\begin{array}{l}\text { Sí, porque nos } \\
\text { podemos quedar } \\
\text { misios [pobres] }\end{array}$ & $\begin{array}{c}\text { No mucho, porque cuando } \\
\text { venga J esús todo eso ya no va } \\
\text { a servir }\end{array}$ \\
\hline $\begin{array}{c}\text { ¿Qué animalitos se } \\
\text { puede matar? ¿Por } \\
\text { qué? }\end{array}$ & $\begin{array}{l}\text { Las hormigas } \\
\text { porque son } \\
\text { pequeñitas }\end{array}$ & $\begin{array}{c}\text { El pez porque tiene } \\
\text { escamas }\end{array}$ & $\begin{array}{c}\text { Los animales que tengan } \\
\text { escama o que no sean impuros, } \\
\text { porque Dios dijo eso y } \\
\text { nosotros le tenemos que hacer } \\
\text { caso }\end{array}$ \\
\hline $\begin{array}{c}\text { ¿Existen niños que } \\
\text { sean superiores } 0 \\
\text { inferiores a ti? ¿Por } \\
\text { qué? }\end{array}$ & $\begin{array}{l}\text { No, porque Dios } \\
\text { nos hizo iguales }\end{array}$ & $\begin{array}{l}\text { Inferiores, porque yo } \\
\text { tengo un amigo en } \\
\text { mi salón que es } \\
\text { inferior }\end{array}$ & $\begin{array}{c}\text { Sí, porque hay niños que saben } \\
\text { más que yo y hay niños que no } \\
\text { saben casi nada }\end{array}$ \\
\hline $\begin{array}{l}\text { ¿Cuál es el horario } \\
\text { más adecuado para } \\
\text { dormir? }\end{array}$ & A las 6:00 pm. & A las $8.00 \mathrm{pm}$. & $\begin{array}{c}\text { 7:30 pm. a 8:30 pm. por lo } \\
\text { menos }\end{array}$ \\
\hline $\begin{array}{l}\text { ¿Qué cosas no puedo } \\
\text { hacer con mis } \\
\text { hermanos? }\end{array}$ & $\begin{array}{l}\text { Pegarles, gritarles, } \\
\text { maltratarles }\end{array}$ & $\begin{array}{l}\text { Pegarles de } \\
\text { cachetadas }\end{array}$ & $\begin{array}{l}\text { No puedo pegarles, tengo que } \\
\text { respetarlos y no tengo que } \\
\text { gritarles }\end{array}$ \\
\hline
\end{tabular}

cómo la sociedad está afectando la formación y cuáles son los puntos débiles del hogar, en este quehacer.

La técnica de la encuesta sobre conocimientos, valores, principios y conductas, consiste en un sencillo cuestionario, que permite evaluar de forma efectiva estos aspectos, sus preguntas pueden ser incrementadas o modificadas dependiendo del propósito del padre, en este caso, el 
cuestionario fue sometido a tres hermanos, el niño 01 aún no ha ido a la escuela, el niño 02 tiene dos años en la escuela y el niño 03 tiene 4 años en la escuela.

La primera pregunta evalúa conocimientos, en ella se puede ver que los niños 01 y 03 no tienen al creacionismo como base para su respuesta, esto no quiere decir que ellos sean evolucionistas, pero sí indica a los padres un tema de conversación importante.

La pregunta cuatro evalúa valores, y nuevamente las respuestas dadas por los niños 01 y 03 presentan una realidad que no siempre es fácilmente visualizada en el hogar, ambos piensan que está permitido mentir en ciertos momentos. Ante tal descubrimiento los padres deben analizar todos los factores internos y externos que están haciendo que se forme esa idea en la mente del niño y elaborar un plan de contingencia.

La pregunta 06 que tiene como propósito evaluar un principio vital, el respeto por la vida, muestra otra realidad que debe ser abordada por los padres, porque los tres niños creen que matar está permitido y que aún ello hace parte de la voluntad de Dios.

Las dos últimas preguntas evalúan conductas y aunque ellas no revelan conductas indeseables en los tres niños, las respuestas a la última pregunta, revela que para ellos la mala conducta sólo está relacionada al trato físico o verbal que se den entre ellos.

Como ya se dijo, todo padre puede crear su propio cuestionario, para ello no hay necesidad de ser un investigador calificado, hacerlo será de gran ayuda para dos cosas: 1) ver los puntos en los que se está fallando y aquellos en los que la sociedad está deformando la mentalidad y el carácter de los niños, y 2) elaborar estrategias que contrarresten los efectos deformantes que la sociedad esté teniendo sobre el carácter de los hijos.

\section{Conclusión}

Educando contra la corriente, no sólo es el título de un artículo, es una realidad que enfrenta todo verdadero cristiano en el quehacer de la formación del carácter de los hijos. Luego 
de desarrollado este artículo, se pueden hacer las siguientes conclusiones.

1. Un hijo es la herencia de Jehová, un ser humano capaz de ejercer el bien o el mal dependiendo en gran medida de la influencia que sus padres hayan ejercido en él.

2. El carácter idóneo es aquel que - apartándose de los conceptos sociales -, refleja el carácter divino, es decir, se construye gracias al acto consciente de imitar el carácter del modelo terrestre de la divinidad, el Señor Jesús.

3. La sociedad, no cumple su función bíblica, sino que es contraria a la Biblia y en gran medida contribuye a la deformación del carácter, y

4. Aunque parezca una tarea imposible, formar un carácter idóneo - perfecto- desde el punto de vista bíblico, esto puede ser hecho y es un deber de todo padre cristiano.

Al formar el carácter de los hijos, todo padre puede crear métodos y técnicas que basadas en la palabra de Dios, lo ayuden a identificar los frentes en los que debe reforzar la lucha que enfrenta con la sociedad, sólo aś podrá asegurar el éxito en este emprendimiento. 